\title{
REG3A promotes the proliferation, migration, and invasion of gastric cancer cells
}

\author{
This article was published in the following Dove Press journal: \\ OncoTargets and Therapy \\ 6 April 2017 \\ Number of times this article has been viewed
}

\author{
Zhou-Feng Chen \\ Zhi-Ming Huang \\ Hai-Bo Xue \\ Xiu-Qing Lin \\ Ren-Ping Chen \\ Meng-Jun Chen \\ Rui-Fang Jin \\ Department of Gastroenterology \\ and Hepatology, The First Affiliated \\ Hospital of Wenzhou Medical \\ University, Wenzhou, People's \\ Republic of China
}

Correspondence: Rui-Fang Jin Department of Gastroenterology and Hepatology, The First Affiliated Hospital of Wenzhou Medical University, Shangcai Village, Wenzhou, 325000, People's Republic of China

Tel +8657755578I66

Email jruf87I I I3@I63.com

\begin{abstract}
The mechanism underlying the metastasis of gastric cancer (GC) cells remains elusive. REG3A is considered an oncogene in various cancers, but in GC its role is unclear. Here, we report that the expression of REG3A was significantly increased in the tumor tissues of patients with GC compared with the matched normal tissues. Knockdown of REG3A induced by specific small interfering RNA (siRNA) significantly repressed the proliferation of GC cells for $24 \mathrm{~h}$ or $48 \mathrm{~h}$. Moreover, knockdown of REG3A significantly suppressed the migration, invasion, and adhesion of GC cells in vitro. Furthermore, knockdown of REG3A reduced the phosphorylation of JAK2 and STAT3, and altered the messenger RNA (mRNA) and protein expression levels of E-cadherin, Snail, RhoC, MTA1, MMP-2, and MMP-9. Taken together, REG3A is overexpressed in GC and promotes the proliferation, migration, invasion, and adhesion of GC cells by regulating the JAK2/STAT3 signal pathway. REG3A may be a potential therapeutic target for GC.
\end{abstract}

Keywords: gastric cancer, REG3A, invasion, migration, adhesion

\section{Introduction}

Gastric cancer (GC) is the second leading cause of cancer-related death worldwide. Tumor metastasis contributes to the high mortality of patients with GC. ${ }^{1}$ The 5 -year survival rate of patients with advanced GC is only $5 \%-15 \% .^{2}$ Although patients with early GC have favorable prognoses, most GC patients progress to the advanced stage when diagnosed, owing to the lack of effective biomarkers for early diagnosis. ${ }^{3}$ Therefore, it is important to explore novel biomarker and therapeutic targets for the diagnosis and treatment of GC.

REG3A is a member of the REG protein family and is also named human hepatocarcinoma-intestine-pancreas or human pancreatitis-associated protein. ${ }^{4,5}$ REG3A messenger RNA (mRNA) can be detected in the pancreas and small intestine, but no evidence showed its expression in the kidney, lung, or brain. REG3A is a secreted calcium-dependent lectin protein associated with the regeneration of pancreatic islet and liver cells and the activation of pancreatic stellate cells. ${ }^{6,7}$ REG3A has been shown to be involved in the development of various cancers, including hepatocellular carcinoma, colorectal cancer, and GC. During liver tumorigenesis, REG3A is a target of the Wnt pathway and is associated with the mutations of $\beta$-catenin. REG3A was found to be downregulated in $67 \%$ of primary human GCs. ${ }^{4}$ However, the role of REG3A in the progression of GC remains largely unclear.

In the present study, we found that the expression of REG3A was significantly elevated in GC tissues compared with the matched normal tissues, and a high expression of REG3A was associated with the patients' poor survival. We further demonstrated 
that REG3A promoted the proliferation, migration, and invasion of GC cells through activation of the JAK2/STAT3 pathway.

\section{Materials and methods}

\section{Patients and samples}

Forty-one patients with GC were enrolled in this study according to the protocols approved by the Ethics Committee of First Affiliated Hospital of Wenzhou Medical University. All patients provided written informed consent for the use of their tissues and data in this study. The clinical characteristics of the patients are shown in Table 1.

\section{Cell culture}

GC cell lines MKN-45, MFC, SGC-7901, and MGC-803 were purchased from the Shanghai Cell Bank, Chinese Academy of Sciences (Shanghai, People's Republic of China). Cells were cultured with Dulbecco's Modified Eagle's Medium (DMEM) (Hyclone, Logan, UT, USA) supplemented with $10 \%$ fetal bovine serum, 100 unit $/ \mathrm{mL}$ penicillin, and $100 \mu \mathrm{g} / \mathrm{mL}$ streptomycin, at $37^{\circ} \mathrm{C}$ in $5 \% \mathrm{CO}_{2}$.

\section{Small interfering RNA (siRNA) transfection}

SGC7901 cells were transfected with $50 \mathrm{nmol} / \mathrm{L}$ of REG3AsiRNA or negative control by using Lipofectamine ${ }^{\mathrm{TM}} 2000$

Table I The clinical characteristics of patients with GC

\begin{tabular}{ll}
\hline Variables & GC, $\mathbf{N}=\mathbf{4 I}$ \\
\hline Gender & \\
Male & 18 \\
Female & 23 \\
Age, years & \\
Median (range) & $56(33-72)$ \\
>60 & 19 \\
S60 & 22 \\
Tumor location & \\
Body & 14 \\
Antrum & 13 \\
Cardia & 14 \\
Other & 0 \\
Histology & \\
Adenocarcinoma & 27 \\
Mucinous adenocarcinoma & 14 \\
Signet cell cancer & 0 \\
TNM stage & \\
I & 4 \\
II & 14 \\
III & 20 \\
IV & 3 \\
Lymph node status & \\
Metastasis & 29 \\
No metastasis & 12 \\
\hline Abbreviation, gastc &
\end{tabular}

Abbreviation: GC, gastric cancer.
(Invitrogen, Shanghai, People's Republic of China) according to the manufacturer's protocols. After $48 \mathrm{~h}$, the cells were collected for further assays.

\section{Cell proliferation assay}

Cell proliferation was assessed by using Cell Counting Kit-8 (CCK-8) (Tongren, Shanghai, People's Republic of China). Briefly, $4 \times 10^{3}$ SGC-7901 cells per well were seeded in 96-well plates and further incubated for $24 \mathrm{~h}$ and $48 \mathrm{~h}$, respectively. CCK-8 reagent was added to each well and incubated for $1 \mathrm{~h}$. The values of optical density $450 \mathrm{~nm}$ in each well were determined by a microplate reader. The experiments were repeated at least three times in triplicate.

\section{Cell invasion assay}

Cell invasion assay was performed by using 24-well trans-well chambers with a pore size of $8 \mu \mathrm{m}$ (Sigma, San Francisco, CA, USA). The inserts were coated with $50 \mu \mathrm{L}$ Matrigel (dilution at 1:2; BD Bioscience, San Jose, CA, USA). $1 \times 10^{5}$ SGC-7901 cells were collected and resuspended in $200 \mu \mathrm{L}$ serum-free DMEM medium and added to the upper chamber. After incubation for $24 \mathrm{~h}$, the cells were fixed with 4\% paraformaldehyde (Zhongze Biotech, Shanghai, People's Republic of China) for $15 \mathrm{~min}$ and stained by $0.1 \%$ crystal violet for $10 \mathrm{~min}$. The number of invaded cells was counted in five randomly selected fields under a microscope (Olympus, Shenzhen, People's Republic of China).

\section{Migration assay}

Cell migration assay was performed by using 24-well transwell chambers with a pore size of $8 \mu \mathrm{m}$ (Sigma). $1 \times 10^{5}$ SGC-7901 cells were collected and resuspended in $200 \mu \mathrm{L}$ serum-free DMEM medium and added to the upper chamber. After incubation for $24 \mathrm{~h}$, the cells were fixed with $4 \%$ paraformaldehyde (Zhongze Biotech) for $15 \mathrm{~min}$ and stained by $0.1 \%$ crystal violet for $10 \mathrm{~min}$. The number of invaded cells was counted in five randomly selected fields under a microscope (Olympus).

\section{Real-time polymerase chain reaction (PCR)}

Total RNA was isolated from GC tissues and the matched normal tissues or SGC-7901 cells using Trizol Reagent (Invitrogen). The cDNA was synthesized from $1 \mu \mathrm{g}$ total RNA using avian myeloblastosis virus (AMV) reverse transcriptase (Fermentas, Waltham, MA, USA) according to the manufacturer's protocols. PCR parameters were 
as follows: $95^{\circ} \mathrm{C}$ for $1 \mathrm{~min}, 30$ cycles at $95^{\circ} \mathrm{C}$ for $15 \mathrm{sec}$, $55^{\circ} \mathrm{C}$ for $10 \mathrm{sec}$, and $72^{\circ} \mathrm{C}$ for $30 \mathrm{sec}$, and then incubated at $72^{\circ} \mathrm{C}$ for $2 \mathrm{~min}$. The sequences of primers were as follows: REG3A 5'-TAATGTGAGGTTACCCTATG-3' and $5^{\prime}$-GAGGAAGAAACAGAAGAAAG-3'; GAPDH 5'-CACCCACTCCTCCACCTTTG-3' and 5'-CCACCACCCTGTTGCTGTAG-3'. The mRNA expression of REG3A was calculated using the $\Delta \Delta \mathrm{Ct}$ method. All data represent the mean of three replicates, with error bars indicating standard deviation (SD).

\section{Western blot analysis}

SGC-7901 cells were harvested and lysed in ice-cold radio immunoprecipitation assay buffer (Beyotime, Shanghai, People's Republic of China) supplemented with protease and phosphatase inhibitors cocktail (Sigma, Shanghai, People's Republic of China). Cell lysate was centrifuged at 13,000 rpm for $10 \mathrm{~min}$ at $4^{\circ} \mathrm{C}$, and the supernatant (20 $\mu \mathrm{g}$ proteins) was run on $10 \%$ SDS-PAGE gel and then transferred onto polyvinylidene fluoride membranes (Millipore, Shanghai, People's Republic of China). The membranes were blocked with 5\% skimmed milk for $1 \mathrm{~h}$ and then incubated with antibodies for REG3A (Abcam), GAPDH (Fermentas), p-JAK2 and JAK2 (CST), RhoC (CST), MTA1 (CST), E-cadherin
(Abcam), Vimentin (Abcam), Snial (Abcam), MMP-2/9 (Abcam), p-STAT3, and STAT3 (CST). The membranes were incubated with goat antimouse or antirabbit secondary antibodies (Beyotime) and then visualized using enhanced chemiluminescence (ECL, Thermo Scientific, Shanghai, People's Republic of China).

\section{Statistical analysis}

All results are presented as the mean $\pm \mathrm{SD}$, and the data were analyzed using a Statistical Package for the Social Sciences (SPSS) 13.0 statistical package (SPSS Inc., Chicago, IL, USA). Data for multiple comparisons were analyzed by one-way analysis of variance and Dunnett's test. $P<0.05$ was considered significant.

\section{Results}

The expression of REG3A is frequently increased in GC tissues and cells

To determine the expression of REG3A in tumor tissues of the GC patients, we detected the expression levels of REG3A in GC tissues and the matched normal tissues. The results showed that mRNA expression of REG3A was significantly elevated in the GC tissues compared with the matched normal tissues $(P<0.01)$ (Figure 1A).
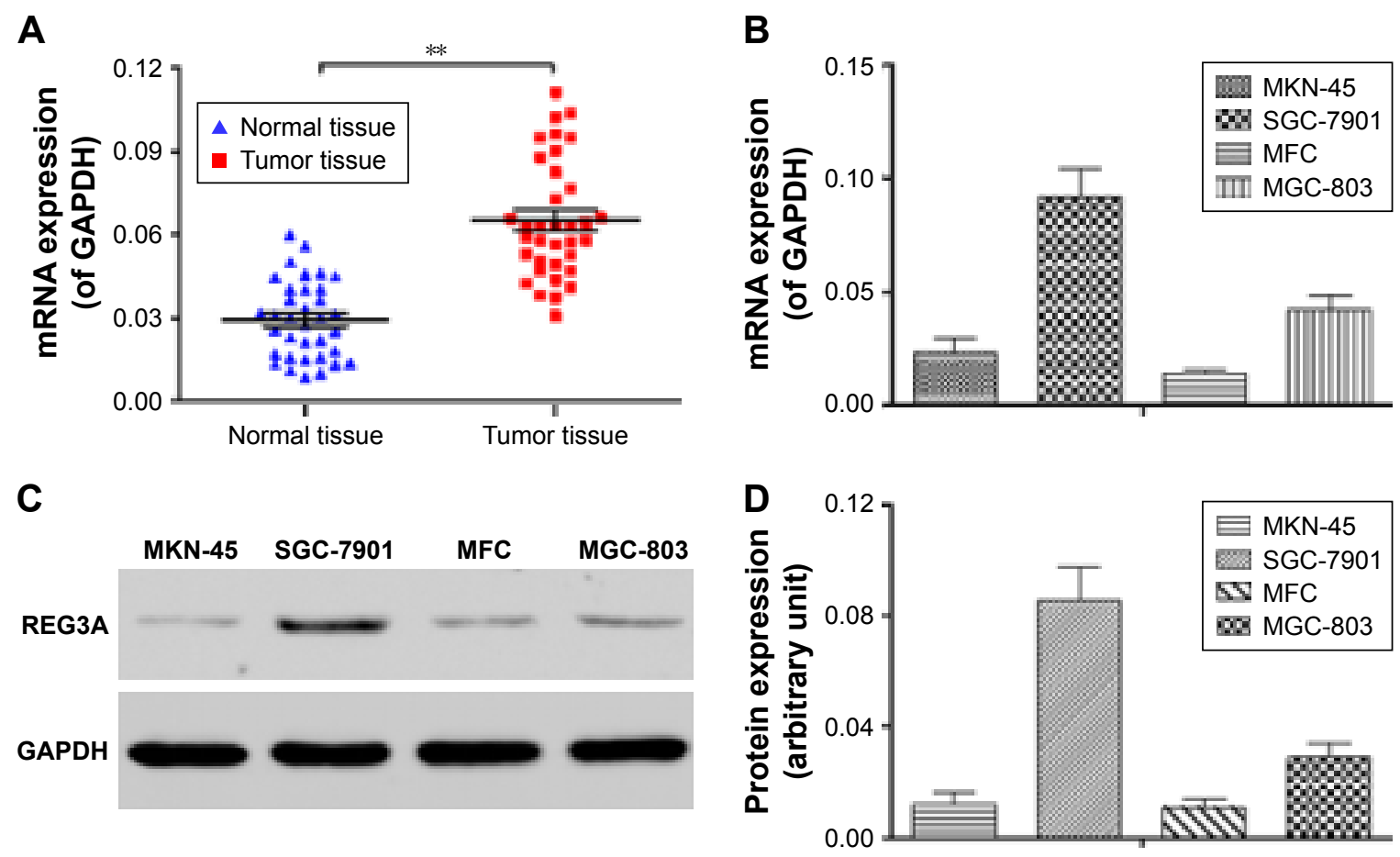

Figure I REG3A expression in GC tissues and cell lines.

Notes: (A) mRNA expression of REG3A in 41 pairs of GC and the matched normal tissues. (B) mRNA expression of REG3A in GC cell lines, including AGS, N87, SGC-790I, and BGC823. (C and D) Western blot analysis of REG3A level in GC cell lines. $* * P<0.01$. Data are expressed as the mean \pm SD ( $n=3$ ).

Abbreviations: GC, gastric cancer; mRNA, messenger RNA; SD, standard deviation. 
In addition, we detected $\mathrm{mRNA}$ and protein expression of REG3A in GC cell lines including MKN-45, MFC, SGC-7901, and MGC-803. As shown in Figure 1B-D, mRNA and protein expression of REG3A were significantly higher in SGC-7901 cells than in the other cells. Therefore, we used SGC-7901 cells to investigate the role of REG3A in GC.

\section{REG3A knockdown significantly represses the proliferation of GC cells}

To determine the function of REG3A in GC cells, we used specific siRNA to knockdown REG3A in SGC-7901 cells. The results showed that the specific siRNA significantly inhibited the mRNA and protein expression of REG3A $(P<0.01)$ (Figure $2 \mathrm{~A}-\mathrm{C})$. We further found that REG3A knockdown significantly repressed the proliferation of $\mathrm{GC}$ cells $(P<0.01)$ (Figure 2D).

\section{REG3A knockdown significantly suppresses the invasion and migration of GC cells}

To understand the role of REG3A in the metastasis of GC cells, we evaluated the migration and invasion of GC cells with REG3A knockdown. The results showed that REG3A
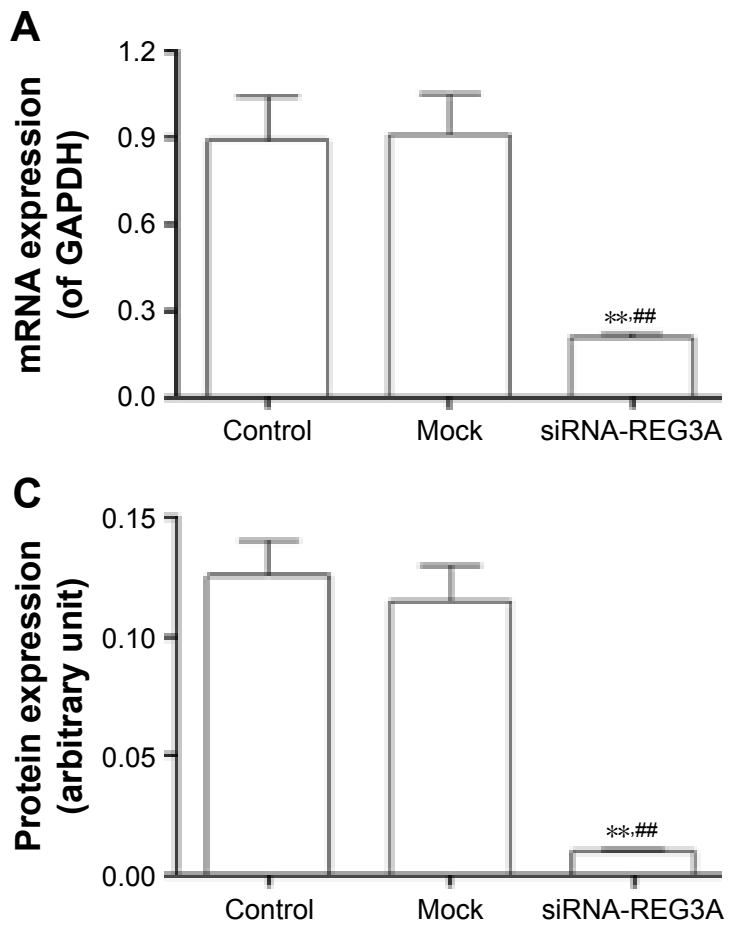

knockdown significantly repressed the migration and invasion of SGC-7901 cells $(P<0.01)$ (Figure 3A and B). These results suggest that REG3A promotes the metastasis of GC.

\section{REG3A knockdown inhibits the activation of JAK2/STAT3 signaling}

JAK/STAT signaling is associated with cell proliferation, migration, and invasion, and REG3A could activate JAK2/STAT3 signaling in pancreatic cancer cells. ${ }^{6}$ Thus, we investigated whether REG3A also activated JAK2/ STAT3 signaling in GC cells. After REG3A knockdown, the phosphorylation levels of p-JKA2 and p-STAT3 were significantly reduced, but the total protein levels of JAK2 and STAT3 were not significantly changed in SGC-7901 cells (Figure 4).

\section{REG3A regulates the expression of invasion and migration-related genes}

E-cadherin, a tumor suppressor, serves as a prognostic biomarker for esophageal cancer. ${ }^{8,9}$ Vimentin plays a crucial role in carcinoma cell adhesion. ${ }^{8}$ Snail is considered a key transcription factor involved in the expression of E-cadherin. ${ }^{9,10}$ MMPs, especially MMP-2 and MMP-9,

B
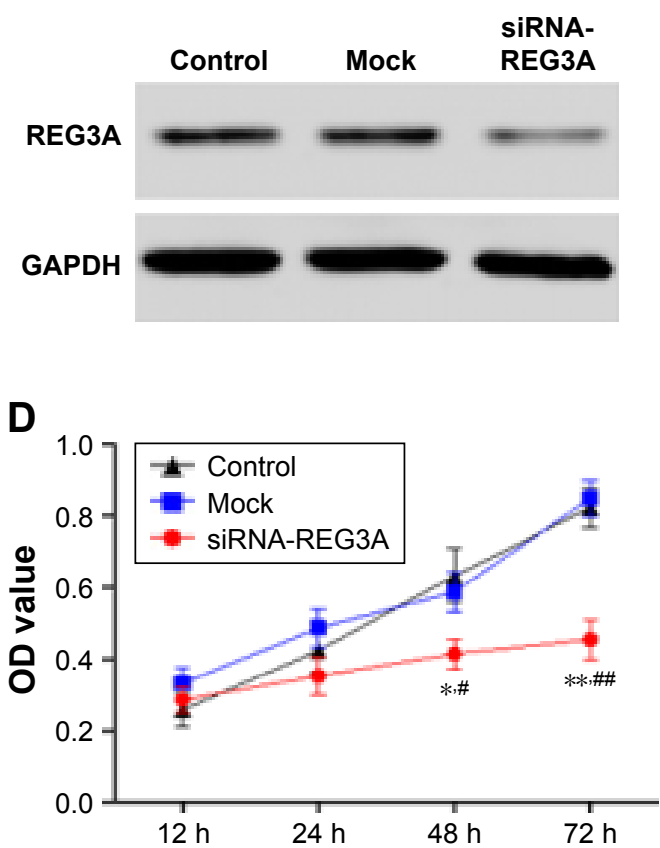

Figure 2 REG3A knockdown suppressed the proliferation of GC cells.

Notes: (A) mRNA expression of REG3A was significantly decreased in SGC-790I cells $48 \mathrm{~h}$ after the transfection of REG3A siRNA. (B and C) The protein expression of REG3A was significantly decreased in SGC-790I cells $48 \mathrm{~h}$ after the transfection of REG3A siRNA. (D) CCK-8 assay of the proliferation of GC cells I2, 24, 48, and 72 h after the transfection of REG3A siRNA; * and ${ }^{\#} P<0.05$; $* *$ and ${ }^{\# P} P 0.01$. Data are expressed as the mean \pm SD $(n=6)$.

Abbreviations: CCK-8, Cell Counting Kit-8; GC, gastric cancer; mRNA, messenger RNA; OD, optical density; SD, standard deviation; siRNA, small interfering RNA. 
A

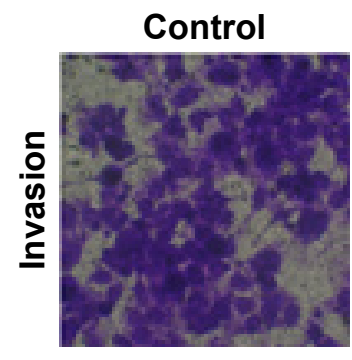

B

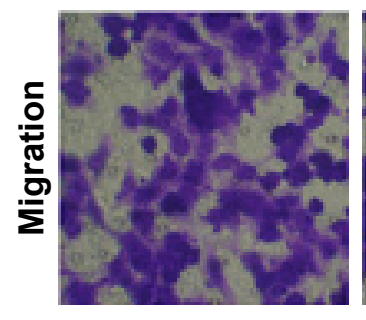

Mock
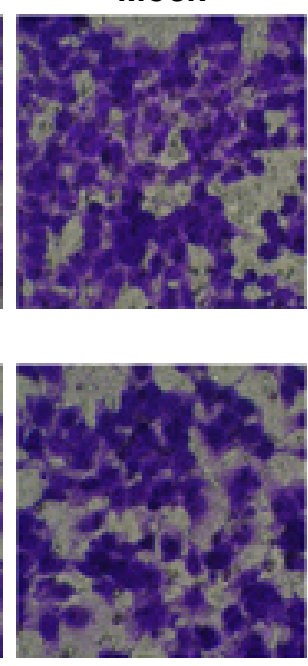

SIRNA-REG3A
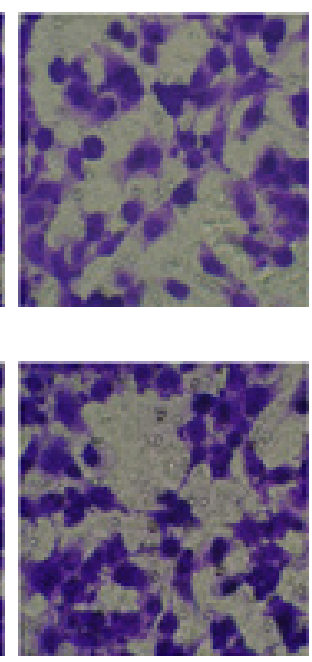
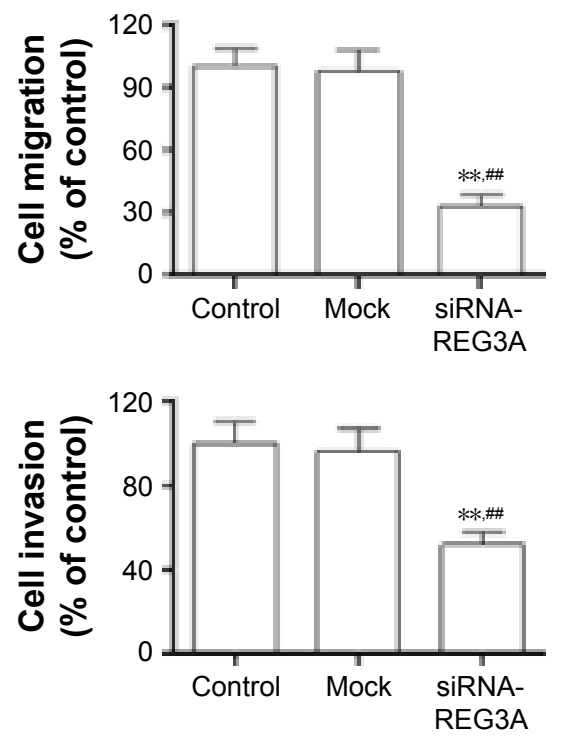

Figure 3 REG3A knockdown suppressed the migration and invasion of GC cells.

Notes: Trans-well assays of the invasion (A) and migration (B) of SGC-790I cells $48 \mathrm{~h}$ after the transfection of REG3A siRNA; ** and ${ }^{\#}<0.01$. Data are expressed as the mean \pm SD $(n=6)$.

Abbreviations: GC, gastric cancer; SD, standard deviation; siRNA, small interfering RNA.

are strongly associated with the progression of human cancers. ${ }^{11,12}$ Therefore, we wondered whether REG3A could regulate the expression of these proteins. Western blot analysis showed that Snail, MMP-2, and MMP-9 protein levels significantly decreased, while E-cadherin, RhoC, and MTA1 protein levels significantly increased in SGC-7901 cells with REG3A knockdown (Figure 5A-C).

\section{Discussion}

In the present study, we confirmed that the expression of REG3A was significantly increased in GC tissues compared with the matched normal tissues, and its overexpression was associated with poor survival of GC patients. Knockdown of
REG3A could repress the proliferation, migration, and invasion of GC cells in vitro. Furthermore, REG3A knockdown inhibited the activation of the JAK/STAT pathway. Several members of the REG protein family such as REG1, REG3A, and REG4 have been found to be upregulated in GC. ${ }^{13-15}$ However, the role of REG3A in GC remains largely unclear. Choi et $\mathrm{al}^{4}$ reported that the mRNA expression of REG3A was downregulated in primary human GCs. In contrast, our data suggest that REG3A acts as a potential oncogene to promote aggressive progression of GC. The reasons for the discrepancy remain unclear; one possibility is the different stages of GC samples used in different studies. Further clinical studies enrolling large samples of GC patients would help
A

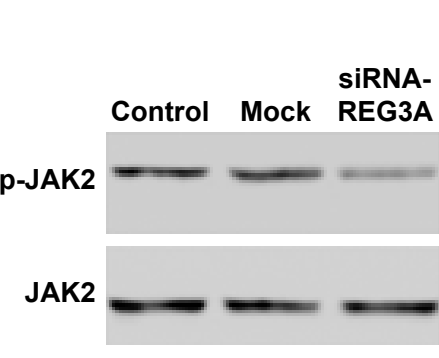

B

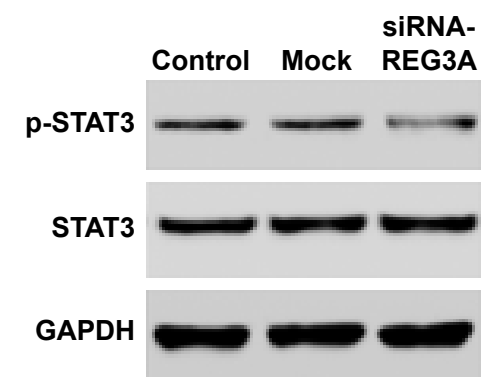

C

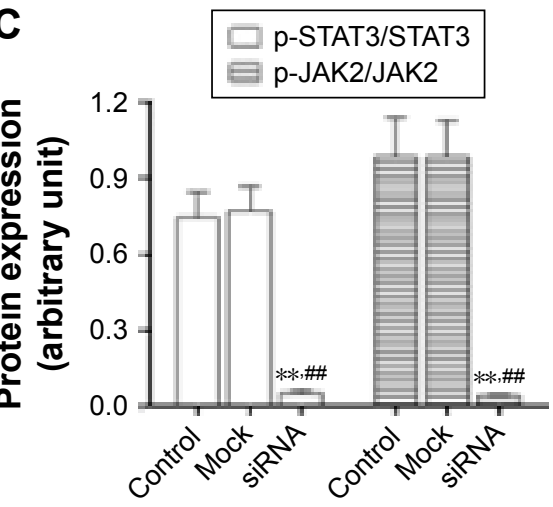

Figure 4 REG3A regulated the JAK2/STATS signal pathway in GC cells.

Notes: Western blot analysis of the phosphorylation levels of JAK2 (A) and STAT3 (B) in SGC-790I cells $48 \mathrm{~h}$ after the transfection of REG3A siRNA. (C) Densitometry analysis of phosphorylated JAK2 and STAT3 levels in SGC-790 I cells; ${ }^{* *}$ and ${ }^{\# P} P<0.01$. Data are expressed as the mean \pm SD ( $n=6$ ).

Abbreviations: GC, gastric cancer; SD, standard deviation; siRNA, small interfering RNA. 
A
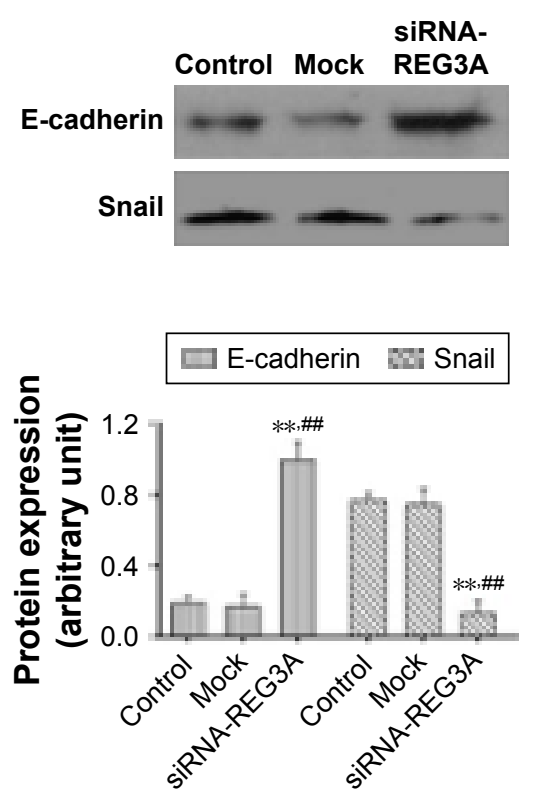

B
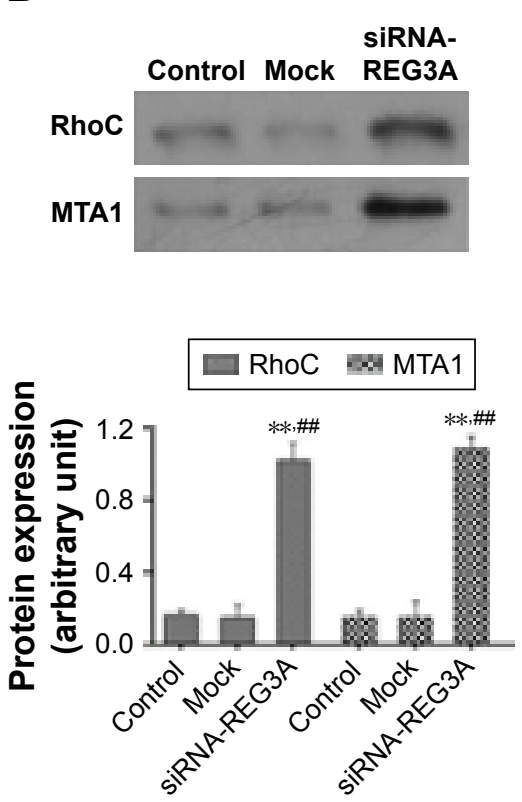

C
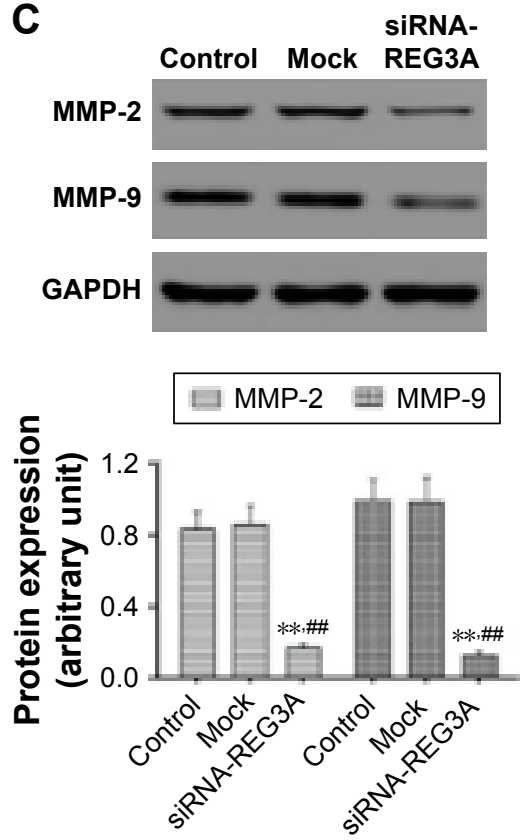

Figure 5 REG3A regulated the expression of multiple cancer-related genes.

Notes: The protein levels of E-cadherin (A), RhoC and MTAI (B) were significantly increased, while those of Snail (A), MMP-2 and MMP-9 (C) were significantly decreased in SGC-790 I cells $48 \mathrm{~h}$ after the transfection of REG3A siRNA. GAPDH was loading control. ** and ${ }^{\#} P<0.01$. Data are expressed as the mean \pm SD ( $=6$ ).

Abbreviation: siRNA, small interfering RNA.

determine the expression status of REG3A in GC. Matsumura et $\mathrm{al}^{14}$ employed microarray analysis to show that REG3A was overexpressed in GC cells. These data support our findings that REG3A is overexpressed and acts as an oncogene in the development of GC.

The function of REG3A has been well studied in other cancers. For example, the upregulation of REG3A could regulate pancreatic cell growth by activating several signal pathways such as TGF- $\beta$, PDGF, and RAS. ${ }^{16,17}$ REG3A promoted the proliferation, migration, and invasion of colorectal cancer cells by activating the AKT and ERK1/2 pathways. ${ }^{18}$ In our study, we found that knockdown of REG3A inhibited the proliferation, migration, and invasion of GC cells, and this was related to the regulation of the JAK2/ STAT3 signal pathway and the expression of E-cadherin, Snail, RhoC, MTA1, MMP-2, and MMP-9. These results suggest that REG3A plays a crucial role in the tumorigenesis of GC.

The activation of the JAK/STAT signal pathway contributes to carcinogenesis. ${ }^{19}$ Increasing evidence reveals that the activation of STAT3 enhances cancer metastasis and invasion. ${ }^{20,21}$ In the present study, the phosphorylation of JAK2 and STAT3 was significantly inhibited by REG3Aspecific siRNA, suggesting that REG3A regulates the JAK2/ STAT3 signal pathway. Tumor cell invasion starts with the breakdown of the extracellular matrix, which involves type IV collagen-degrading enzymes, including MMP-2 and MMP-9..$^{22,23}$ We found that REG3A regulated the expression of MMP-2 and MMP-9 in GC cells, which may explain the oncogenic role of REG3A in GC. However, our study is in vitro and further in vivo experiments are needed to confirm that REG3A acts as an oncogene in GC.

\section{Conclusion}

Our study suggests that REG3A promotes the progression of GC via the activation of the JAK2/STAT3 signal pathway and the regulation of the expression of multiple cancerrelated genes. REG3A is a promising therapeutic target for the treatment of GC.

\section{Acknowledgment}

This work is supported by the Scientific Research Foundation of Henan (No. 092102310090).

\section{Disclosure}

The authors report no conflicts of interest in this work.

\section{References}

1. Plichta JK, Rai U, Tang R, et al. Factors associated with recurrence rates and long-term survival in women diagnosed with breast cancer ages 40 and younger. Ann Surg Oncol. 2016;23(10):3212-3220.

2. Nonoshita T, Otsuka S, Inagaki M, Iwagaki H. Complete response obtained with S-1 plus CDDP therapy in a patient with multiple liver metastases from gastric cancer. Hiroshima J Med Sci. 2015;64(4):65-69. 
3. Tong W, Ye F, He L, et al. Serum biomarker panels for diagnosis of gastric cancer. Onco Targets Ther. 2016;9:2455-2463.

4. Choi B, Suh Y, Kim WH, Christa L, Park J, Bae CD. Downregulation of regenerating islet-derived 3 alpha (REG3A) in primary human gastric adenocarcinomas. Exp Mol Med. 2007;39(6):796-804.

5. Lai Y, Li D, Li C, et al. The antimicrobial protein REG3A regulates keratinocyte proliferation and differentiation after skin injury. Immunity. 2012;37(1):74-84

6. Liu X, Wang J, Wang H, et al. REG3A accelerates pancreatic cancer cell growth under IL-6-associated inflammatory condition: involvement of a REG3A-JAK2/STAT3 positive feedback loop. Cancer Lett. 2015; 362(1):45-60.

7. Wang J, Zhou H, Han Y, et al. SOCS3 methylation in synergy with Reg3A overexpression promotes cell growth in pancreatic cancer. J Mol Med. 2014;92(12):1257-1269.

8. Ivaska J, Pallari HM, Nevo J, Eriksson JE. Novel functions of vimentin in cell adhesion, migration, and signaling. Exp Cell Res. 2007;313(10): 2050-2062.

9. Nieto MA. The snail superfamily of zinc-finger transcription factors. Nat Rev Mol Cell Biol. 2002;3(3):155-166.

10. Zhou BP, Deng J, Xia W, et al. Dual regulation of Snail by GSK-3betamediated phosphorylation in control of epithelial-mesenchymal transition. Nat Cell Biol. 2004;6(10):931-940.

11. Zhang DH, Zhang LY, Liu DJ, Yang F, Zhao JZ. Expression and significance of MMP-9 and MDM2 in the oncogenesis of lung cancer in rats. Asian Pac J Trop Med. 2014;7(7):585-588.

12. Sun S, Henriksen K, Karsdal MA, et al. Measurement of a MMP-2 degraded Titin fragment in serum reflects changes in muscle turnover induced by atrophy. Exp Gerontol. 2014;58:83-89.

13. Steele IA, Dimaline R, Pritchard DM, et al. Helicobacter and gastrin stimulate Reg1 expression in gastric epithelial cells through distinct promoter elements. Am J Physiol Gastrointest Liver Physiol. 2007; 293(1):G347-G354.
14. Matsumura N, Zembutsu H, Yamaguchi K, et al. Identification of novel molecular markers for detection of gastric cancer cells in the peripheral blood circulation using genome-wide microarray analysis. Exp Ther Med. 2011;2(4):705-713.

15. Wang $\mathrm{H}, \mathrm{Hu} \mathrm{L}$, Zang $\mathrm{M}$, et al. REG4 promotes peritoneal metastasis of gastric cancer through GPR37. Oncotarget. 2016;7(19): 27874-27888

16. Xu Q, Fu R, Yin G, Liu X, Liu Y, Xiang M. Microarray-based gene expression profiling reveals genes and pathways involved in the oncogenic function of REG3A on pancreatic cancer cells. Gene. 2016;578(2):263-273

17. Ye Y, Xiao L, Wang SJ, et al. Up-regulation of REG3A in colorectal cancer cells confers proliferation and correlates with colorectal cancer risk. Oncotarget. 2016;7(4):3921-3933.

18. Li W, Liu H, Yu M, et al. Folic acid alters methylation profile of JAKSTAT and long-term depression signaling pathways in Alzheimer's disease models. Mol Neurobiol. 2016;53(9):6548-6556.

19. Swierkot J, Sokolik R, Czarny A, et al. Activity of JAK/STAT and NF-kB in patients with axial spondyloarthritis. Postepy Hig Med Dosw (Online). 2015;69:1291-1298.

20. Sasazawa Y, Sato N, Suzuki T, Dohmae N, Simizu S. C-Mannosylation of thrombopoietin receptor (c-Mpl) regulates thrombopoietindependent JAK-STAT signaling. Mol Cell Biol Res Commun. 2015; 468(1-2):262-268.

21. Rabadan R, Inghirami G. JAK-STAT in lymphoproliferative disorders Oncoscience. 2015;2(9):737-738.

22. Bobinska K, Szemraj J, Czarny P, Galecki P. Role of MMP-2, MMP-7, MMP-9 and TIMP-2 in the development of recurrent depressive disorder. J Affect Disord. 2016;205:119-129.

23. Qu H, Li J, Wu LD, Chen WP. Trichostatin A increases the TIMP-1/ MMP ratio to protect against osteoarthritis in an animal model of the disease. Mol Med Rep. 2016;14(3):2423-2430.
OncoTargets and Therapy

\section{Publish your work in this journal}

OncoTargets and Therapy is an international, peer-reviewed, open access journal focusing on the pathological basis of all cancers, potential targets for therapy and treatment protocols employed to improve the management of cancer patients. The journal also focuses on the impact of management programs and new therapeutic agents and protocols on

\section{Dovepress}

patient perspectives such as quality of life, adherence and satisfaction. The manuscript management system is completely online and includes a very quick and fair peer-review system, which is all easy to use. Visit http://www.dovepress.com/testimonials.php to read real quotes from published authors. 